\title{
The Reinforcing Therapist Performance (RTP) experiment: Study protocol for a cluster randomized trial
}

\author{
Bryan R Garner ${ }^{1 *}$, Susan H Godley ${ }^{1}$, Michael L Dennis', Mark D Godley', Donald S Shepard ${ }^{2}$
}

\begin{abstract}
Background: Rewarding provider performance has been recommended by the Institute of Medicine as an approach to improve the quality of treatment, yet little empirical research currently exists that has examined the effectiveness and cost-effectiveness of such approaches. The aim of this study is to test the effectiveness and costeffectiveness of providing monetary incentives directly to therapists as a method to improve substance abuse treatment service delivery and subsequent client treatment outcomes.

Design: Using a cluster randomized design, substance abuse treatment therapists from across 29 sites were assigned by site to either an implementation as usual (IAU) or pay-for-performance (P4P) condition.

Participants: Substance abuse treatment therapists participating in a large dissemination and implementation initiative funded by the Center for Substance Abuse Treatment.

Intervention: Therapists in both conditions received comprehensive training and ongoing monitoring, coaching, and feedback. However, those in the P4P condition also were given the opportunity to earn monetary incentives for achieving two sets of measurable behaviors related to quality implementation of the treatment.

Outcomes: Effectiveness outcomes will focus on the impact of the monetary incentives to increase the proportion of adolescents who receive a targeted threshold level of treatment, months that therapists demonstrate monthly competency, and adolescents who are in recovery following treatment. Similarly, cost-effectiveness outcomes will focus on cost per adolescent receiving targeted threshold level of treatment, cost per month of demonstrated competence, and cost per adolescent in recovery.
\end{abstract}

Trial Registration: Trial Registration Number: NCT01016704

\section{Background}

Alcohol and other drug abuse problems are increasingly being recognized as a chronic, relapsing condition that may last for decades and require multiple episodes of care over many years [1-3]. As over $80 \%$ of all people who develop alcohol and other substance use disorders start using under the age of 18 [4], there is clearly a need for effective treatment interventions designed specifically for adolescents. Unfortunately, while a number of effective evidence-based treatments (EBTs) have been developed for treating adolescent substance abuse and dependence [5-14], the diffusion of such EBTs into

\footnotetext{
* Correspondence: brgarner@chestnut.org

'Lighthouse Institute, Chestnut Health Systems, Normal, IL, USA
}

practice settings has been found to be a significant challenge [15-18].

Since the identification of this important issue, there has been great interest in bridging the 'research-to-practice gap', including research to understand the correlates of EBT adoption $[19,20]$ and staff attitudes toward EBT use [21-23]. Additionally, several conceptual models of the EBT adoption and implementation process have been developed [24-27]. Despite these advances, there remains much room for further improvement, especially in the identification of methods that facilitate implementation of EBTs $[18,28,29]$. This is a critically important area of research, given meta-analyses of treatment programs have suggested that the degree of implementation can be as important as the nominal efficacy of the 
targeted EBT, with the biggest effects coming from wellimplemented, highly efficacious interventions [30]. In order to reliably achieve effective treatment outcomes, it is necessary to empirically test ways to improve the EBT implementation process in practice settings.

While multiple factors influence the quality and degree of EBT implementation in practice settings, attention has increasingly focused on the role of the therapist as a key mediator of treatment delivery over the last decade [31-34]. Indeed, Walters, Matson, Baer, and Ziedonis [35] conducted a systematic review of the effectiveness of workshop training for psychosocial addiction treatments and concluded that workshop trainings generally improved therapist knowledge, attitude, and confidence in working with clients, as well as some skills immediately after training. However, they also found that these skills typically were not maintained for very long. In order for therapists to incorporate these skills in their repertoire for the long-term, they concluded that extended contact, including feedback, supervision, and consultation, is also necessary. Support for this conclusion is perhaps best provided by the studies that used experimental designs to test different training strategies [33,34]. For example, Miller and colleagues [33] evaluated four methods to help therapists learn motivational interviewing (MI), including: workshop only; workshop plus practice feedback; workshop plus individual coaching; and workshop, feedback, and coaching. Only therapists in the full training condition (i.e., workshop, feedback, and coaching) had clients with significant changes in their response to treatment. However, even these state-of-the-art training and technical assistance strategies may not be enough to ensure quality implementation, as even within carefully controlled clinical trials that employ these strategies, there is often variation in how competently and reliably therapists implement interventions. For example, in an examination of the relationship between therapist competence and clinical outcomes in the Treatment of Depression Collaborative Research Program (TDCRP), Shaw et al. [36] found that therapists did not meet the set minimum standard for competence in $27 \%$ of sessions. Indeed, in multiple studies that examined this issue, the size of the 'therapist' effect has been as large as or larger than the mean effects between conditions [37-42].

Given therapists are critical in the implementation of high-quality treatment, research is needed to better understand how to improve the degree to which therapists competently deliver EBTs to adolescents. One approach recently recommended by the Institute of Medicine is called pay-for-performance (P4P), and is a variant of contingency management procedures (also called motivational incentives) that have been shown to be effective in the enhancement of a variety of behaviors with alcohol and other substance abusers [43-50]. Interestingly, despite several studies having demonstrated the significant relationship between financial incentives and work performance [51-54], few studies have used randomized clinical trials (RCTs) to examine the impact of P4P initiatives within healthcare [55] or behavioral health [56]. Although not RCTs, there are several notable examples of linking monetary incentives to performance within the substance abuse treatment field [57-59]. For instance, Andrzejewski et al. [57] found that providing graphical performance feedback and drawings for cash incentives increased implementation by $69 \%$ and $93 \%$, respectively. Shepard et al. [58] found that providing therapists with a $\$ 100$ bonus was an effective and cost-effective approach to improve the percentage of clients who attended five sessions. McLellan et al. [59] reported on the Delaware Division of Substance Abuse and Mental Health (DSAMH) 'performance contracting' with all 11 of its outpatient addiction treatment programs. Results indicated that 'capacity utilization' increased from an average of $54 \%$ in 2001 to an average of $95 \%$ in 2006 and that active participation' increased from an average of $53 \%$ in 2001 to $70 \%$ in 2006. Although P4P methods appear to hold promise for improving treatment implementation, research utilizing rigorous experimental designs and larger sample sizes is clearly needed.

The current paper describes the design and baseline characteristics of the therapists participating in the Reinforcing Therapist Performance (RTP) study, which is a cluster randomized experiment examining the effectiveness and cost effectiveness (CE) of providing monetary incentives directly to therapists as an innovative method to improve treatment service delivery and subsequent treatment outcomes for adolescents and their caregivers. This study is unique in that there are only a handful of studies that focus on staff characteristics and the mechanisms by which staff behaviors are changed, and even fewer randomized experiments in which staff are the unit of analysis.

\section{Methods}

\section{Overview of conceptual model}

Figure 1 illustrates the conceptual framework for the study, which builds upon the Theory of Planned Behavior (TPB) [60] and work by Meterko and colleagues [61]. Specifically, we hypothesize: therapist achievement of the two behaviors being reinforced as part of the study are directly related to their intentions to achieve these behaviors and indirectly related (via intentions) to their attitude toward the incentives, attitude toward the behavior, subjective norms (i.e., social pressure from significant others to engage or not to engage in a behavior, and perceived level of control (perceived ease or difficulty 
of performing a behavior). We also hypothesize that these antecedents of intentions will be directly related to: being randomized to the P4P condition, psychological climate [62] (i.e., therapist perceptions of the organizational climate), and background characteristics (e.g., age, gender, education level, experience). Finally, we hypothesize achievement of the reinforced targets will be associated with improved adolescent treatment outcomes (e.g., reduced substance use).

\section{Study setting}

Consistent with recommendations from a blue ribbon task force on health services research [63], this study represents a unique collaboration between the National Institute on Alcohol Abuse and Alcoholism (NIAAA) and the Center for Substance Abuse Treatment (CSAT). Indeed, the RTP study would not be feasible without the braiding of NIAAA research dollars and more than $\$ 30$ million dollars from CSAT as part of its Assertive Adolescent and Family Treatment (AAFT) dissemination and implementation initiative. As CSAT's AAFT initiative, which provides the foundational setting for the study, has been described in detail elsewhere (Godley, Garner, Smith, Meyers, \& Godley, 2010), only a brief description is provided here.

Between 2006 and 2007, CSAT awarded three-year grants to 34 community-based organizations across the United States to implement a standardized assessment called the Global Appraisal of Individual Needs (GAIN) and two EBTs called the Adolescent Community Reinforcement Approach (A-CRA) and the Assertive Continuing Care (ACC). The latter are EBT adaptations for adolescents of the Community Reinforcement Approach [64] (CRA), and have been shown to be effective in the treatment of adolescent substance abuse and dependence [8,9,65-68]. The purpose of these demonstration grants are to help address the research-to-practice gap by helping community-based treatment agencies implement effective assessment and treatment practices for adolescents and their families/primary caregivers. Based on the research literature and the center's experience that both training and ongoing consultation/coaching are necessary components of successfully implementing EBTs [24,33,34], CSAT also awarded a contract to Chestnut Health Systems to deliver the GAIN and ACRA/ACC training and technical assistance model to all 34 grantees.

\section{Overview of RTP study design}

This RTP experiment and the rest of this article focus on improving the implementation of A-CRA/ACC. As part of the comprehensive A-CRA/ACC training model received by both RTP groups, participants: read the ACRA manual and pass a knowledge test prior to training; attending a 3.5-day training workshop; participate in bi-weekly telephone coaching calls with treatment model experts; receive quantitative and qualitative feedback on actual session performance throughout the certification process; receive feedback on actual session performance as part of randomly selected post-certification fidelity checks; and provide documentation of treatment implementation via therapist reports of procedures delivered during each treatment session as well as corresponding digital session recordings (DSRs) of the

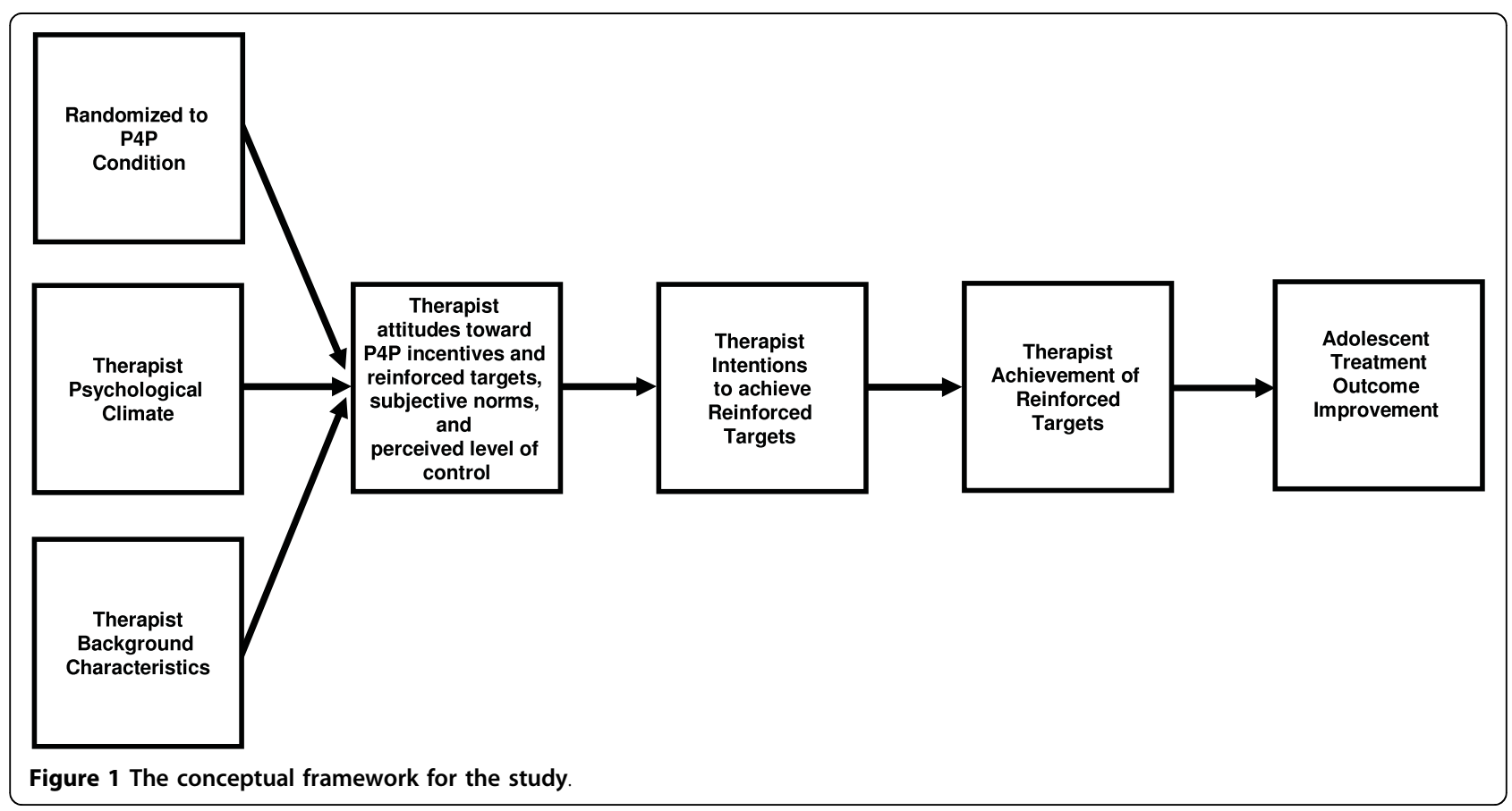


session. Thus, with 34 grantees across 15 states, the AAFT project represents one of the field's largest dissemination and implementation initiatives of an adolescent substance abuse treatment intervention to date. More importantly, the standardized level of funding and training being delivered to the 34 CSAT grantees provides an ideal setting in which to examine methods to improve implementation.

RTP is a cluster randomized experiment examining the effectiveness and $\mathrm{CE}$ of providing monetary incentives to therapists as a method to improve treatment implementation and subsequent outcomes for adolescents and their caregivers. It builds upon prior work by Garner and colleagues [65] that has shown exposure to A-CRA procedures significantly mediates the relationship between treatment retention and outcomes, and empirically identified a threshold level of A-CRA exposure significantly related to positive post-treatment outcomes (i.e., being in recovery). Additionally, it builds upon research that has examined the relationship between therapist competency and treatment outcome for clients $[36,69,70]$. ACRA/ACC sites and therapists within site were recruited to participate in the study, and those who agreed were randomly assigned to either implementation as usual (IAU) or P4P. Participation was voluntary and the study is conducted under the supervision of Chestnut Health Systems Institutional Review Board (IRB). Below are further descriptions of the intervention, procedures, measures, and analytic plans.

\section{Study intervention}

\section{Implementation as usual (IAU)}

Both groups receive the same training and technical assistance model they have been receiving since the inception of the AAFT initiative. As noted above, this state-of-the-art training and technical assistance model consists of a 3.5-day workshop training, bi-weekly telephone coaching calls with model experts, and ongoing monitoring and feedback (both quantitative and qualitative) as part of a standardized certification process.

\section{Pay-for-performance (P4P)}

In addition to the above, the P4P group has the opportunity to earn monetary bonuses for two sets of measurable behaviors related to quality implementation of the model. These two behaviors are: delivering Target ACRA and demonstrating Monthly A-CRA Descriptions of the rationale and reinforcement schedules for these two targeted behaviors are described in the sections below; however, detailed descriptions of Target A-CRA and Monthly A-CRA competency are provided in the study measures section.

\section{Rationale and reinforcement schedule for target A-CRA}

Research has suggested that the degree of implementation can be as important as the efficacy of the EBT, with the biggest effects coming from well-implemented, highly efficacious interventions [30]. Similarly, our prior research [65] has shown that adolescents who received a threshold exposure of A-CRA were significantly more likely to be in recovery at follow-up. Increasing the number of adolescents who receive Target A-CRA would be expected to result in a higher likelihood that adolescents would have more positive treatment outcomes. Thus, one of the questions the study was designed to examine is the extent to which monetary bonuses could increase the probability that an adolescent receives Target A-CRA. As part of the RTP, study therapists in the P4P condition receive a $\$ 200$ bonus for each adolescent who receives Target A-CRA within the first 14 weeks of AAFT and in no fewer than seven ACRA sessions. In order to attribute improvements in adolescent outcomes to the incentives, only outcome data from adolescents admitted to the AAFT project after sites were randomly assigned to the study conditions will be used in Target A-CRA-related analyses.

Rationale and reinforcement schedule for monthly A-CRA competency

In addition to reinforcing exposure to a threshold number of procedures, we believed it was important to reinforce the quality of delivery (i.e., competence). Thus, $\mathrm{P} 4 \mathrm{P}$ therapists also are provided the opportunity to earn a $\$ 50$ bonus for each month that a randomly selected session recording has at least one core procedure rated at or above the minimum level of competence required for certification. Importantly, in order to ensure a representative sample of session recordings, only those therapists who submit at least $80 \%$ or more of treatment session recordings are eligible to have a session rated for competence. Because it would take approximately three months after randomization before P4P participants would be eligible to begin receiving their first bonus associated with delivery of Target A-CRA, reinforcing Monthly A-CRA competency is important as it can be reinforced sooner and more frequently.

\section{Recruitment}

The initial recruitment period for the study occurred between November 2008 and February 2009 and was limited to the sites and therapists participating in CSAT's AAFT initiative. Since the two cohorts of AAFT were funded in different years, recruitment of the study sites was in months 27 and 15 of the cohorts' respective 36-month grants. Although the site's therapists were the target population for the RTP, it was necessary to first obtain permission from each grantee's principal investigator (PI) and/or treatment agency director.

\section{Site recruitment}

Recruitment of study sites began in November 2008. AAFT grantees were first introduced to the study via an email briefly explaining the goals of the study and the extent of involvement the study would require. Email 
attachments included: the memorandum of understanding, which outlined the responsibilities of the study sites, the informed consent, which outlined the responsibilities of the therapist participants, and a signed letter of support from the CSAT project officer. The study PI (BRG) followed up the e-mail introductions with telephone calls with each site PI to answer questions and inquire about the site's willingness to participate in the study. Out of the 34 grantees, two were excluded for study participation because they were not providing services in an outpatient setting, and two were ineligible because they could not be matched to a comparable site for randomization. Of the 30 eligible grantees, 29 (97\%) agreed to participate by returning signed copies of the memorandum of understanding.

\section{Staff recruitment}

Recruitment of therapist participants for the study began one month after site recruitment. In order to be eligible to participate in the study, therapists had to work at one of the participating AAFT grantee sites and be delivering A-CRA or ACC to adolescents. Study packets containing a cover letter, informed consent, staff survey, and a W-9 tax form were mailed to 92 eligible therapists. Of these, 82 (89\%) agreed to participate.

\section{Randomization}

Although random assignment of therapists might appear ideal, a number of issues made such an approach impractical and led to the decision to randomize in clusters by site. For example, dividing small (two- to fourperson) clinical teams within a site through random assignment may lead to unintended consequences due to some therapists being eligible for incentives and others not. For example, the IAU group might work harder than they normally would to achieve goals (i.e., compensatory rivalry), which would threaten the study's internal validity (increasing type 2 error probability). Another possibility is that this situation would lead to resentful demoralization of therapists in the control group, and they would deliver sub-par effort (increasing type 1 error probability). In order to avoid these potential problems, we used an adaptive randomization procedure referred to as urn randomization $[71,72]$ to assign sites to the two study conditions. Shadish, Cook, and Campbell [71] recommend using such adaptive procedures whenever feasible and when good matching variables can be found, and have noted that the best matching variables are pre-test scores on the outcomes of interest.

Given the two cohorts of AAFT grantees were in months 27 and 15 of their respective 36-month grants, pre-test data was available on several important matching variables. Using existing project data on therapists performance and from staff questionnaires (described further below), we created several grantee-level measures including: average Target A-CRA rate; average DSR upload rate; three-month client recovery rate; percentage of Caucasian clients; percentage of Hispanic clients; percentage of male clients; number of therapists; average therapist age; percentage of Caucasian therapists; percentage of male therapists; and AAFT staff ratings of expected performance. This last measure was used to take into account any recent changes (e.g., turnover of supervisor, major improvement/decrements in performance) that might impact performance in the study, and was based upon independent rankings from the director and coordinator of the AAFT training team. Both raters agreed on the rankings for all but two study sites (Kappa $=0.86$ ), and the two raters were able to discuss and resolve these two inconsistencies. Each of the above-mentioned existing measures was then entered by AAFT cohort into an urn randomization software program called gRand.

Although urn randomization was conducted at the site level, it resulted in a balanced distribution of therapists into the two study conditions (See Table 1). Of the 82 therapists used to randomize sites most were female (74.4\%) and Caucasian (56.1\%). They had an average age of 37 years $(\mathrm{SD}=11.6)$. In terms of their education and work experience, most had either a Masters $(52.4 \%)$ or a Bachelor's (41.5\%) degree, with an average of 4.3 years of substance abuse counseling experience. Seven percent reported personally being in recovery for alcohol or other drugs. Based on therapist self-report, the average achievement of Target A-CRA implementation prior to the experiment was $19.2 \%$, and the average session recording rate of fidelity was $41.0 \%$. Based on threemonth post-intake follow-up data prior to the experiment, the average percentage of therapists' adolescent clients in recovery was $45.9 \%$. Notification to sites and individual participants about the official commencement of the study and their assignment to either the IAU or P4P conditions were sent via email on 16 January 2009 for the AAFT-1 and on 13 February 2009 for AAFT-2.

\section{Study measurements}

Given that the primary aims of the study were to examine the effectiveness and CE of providing monetary incentives to therapists as a method to improve treatment implementation and subsequent outcomes for adolescents and their caregivers, it was necessary to collect measures from multiple levels (i.e., therapist, adolescent, and grantee) and over several different time points.

\section{Therapist background and attitude measures}

As noted previously, all study participants completed a staff survey at the time of consenting to participate. This 15-page survey took approximate 30 to 45 minutes and asked questions about the individual and the therapist's work environment. Examples include basic sociodemographic characteristics such as age, race, and 


\begin{tabular}{|c|c|c|c|}
\hline & P4P $(n=42)$ & IAU $(n=40)$ & Overall $(\mathrm{N}=82)$ \\
\hline & $\%$ or $\mathrm{M}(\mathrm{SD})$ & $\%$ or $\mathrm{M}(\mathrm{SD})$ & $\%$ or $\mathrm{M}(\mathrm{SD})$ \\
\hline Age & $36.7(11.3)$ & $36.7(12.2)$ & $36.7(11.6)$ \\
\hline \multicolumn{4}{|l|}{ Race } \\
\hline American Indian/Alaska Native & $2.4 \%$ & $2.5 \%$ & $2.4 \%$ \\
\hline Asian & $0.0 \%$ & $5.0 \%$ & $2.4 \%$ \\
\hline African American & $11.9 \%$ & $17.5 \%$ & $19.5 \%$ \\
\hline Caucasian & $52.4 \%$ & $60.0 \%$ & $56.1 \%$ \\
\hline Hispanic/Latino & $31.0 \%$ & $15.0 \%$ & $23.2 \%$ \\
\hline Other & $2.4 \%$ & $0.0 \%$ & $1.2 \%$ \\
\hline \multicolumn{4}{|l|}{ Gender } \\
\hline Male & $19 \%$ & $32.5 \%$ & $25.6 \%$ \\
\hline Female & $81 \%$ & $67.5 \%$ & $74.4 \%$ \\
\hline \multicolumn{4}{|l|}{ Education } \\
\hline Less than Bachelor's Degree & $0.0 \%$ & $7.5 \%$ & $3.7 \%$ \\
\hline Bachelor's Degree & $47.6 \%$ & $35.0 \%$ & $41.5 \%$ \\
\hline Master's Degree & $50.0 \%$ & $55.0 \%$ & $52.4 \%$ \\
\hline Doctoral Degree & $2.4 \%$ & $2.5 \%$ & $2.4 \%$ \\
\hline Years of SAT Experience & $3.3(3.3)$ & $5.4(7.1)$ & $4.3(5.6)$ \\
\hline Self-reported being in recovery & $7.1 \%$ & $7.5 \%$ & $7.0 \%$ \\
\hline Pre-RTP Target A-CRA Rate & $21.4 \%$ & $16.7 \%$ & $19.2 \%$ \\
\hline Pre-RTP Session Recording Rate & $40.4 \%$ & $41.7 \%$ & $41.0 \%$ \\
\hline Pre-RTP 3-month Client Recovery Rate & $46.5 \%$ & $45.1 \%$ & $45.9 \%$ \\
\hline
\end{tabular}

gender; highest educational degree obtained; and years of substance abuse counseling experience. The survey also included the Minnesota Satisfaction Questionnaire (MSQ) [73], the Pay Satisfaction Questionnaire (PSQ) [74], several scales from the Organizational Readiness for Change (ORC) instrument [75], and several measures adapted from the Provider Attitudes toward Incentive (PAI) [61] instrument. Assessment of changes in participants' attitudes and work environments was measured via three-month follow-up versions of the survey.

\section{Therapist implementation measures}

The two implementation measures being reinforced as part of the study are Target A-CRA and Monthly ACRA Competency. Developed using existing AAFT data, Target A-CRA is a dichotomous $(1=$ yes, $0=$ no $)$ measure. It is defined as the delivery of 10 or more of the following 12 A-CRA procedures: functional analysis of substance using behavior; functional analysis of prosocial behavior; happiness scale; treatment plan/goals of counseling; communication skills; problem solving skills; adolescent-caregiver relationship skills; caregiver overview, rapport building, and motivation; homework reviewed; drink/drug refusal skills; relapse prevention; and increasing prosocial recreation during the first 14 weeks of an adolescent's AAFT treatment experience (but in no fewer than seven sessions). See the A-CRA treatment manual for a description of these A-CRA procedures [76]. Additionally, because identifying, discussing, and reviewing the adolescent's reinforcers is considered a central mechanism of change within the A-CRA philosophy, as part of Target A-CRA, therapists also must demonstrate one of these three components in at least $50 \%$ or more of the sessions conducted during this time period. Therapist-reported data on more than 450 adolescents uploaded to AAFT's implementation tracking system (i.e., https://www.EBTx.org) indicated adolescents who received Target A-CRA had significantly $(p<0.05)$ 
greater reductions in days abstinent at both three- and six- month post-intake assessments. Importantly, although therapist reports are used to identify adolescents who appear to have received Target A-CRA, official achievement of Target A-CRA for the study requires independent verification (via listening to DSR) by a trained A-CRA rater. See Garner, Barnes, and Godley [77] for complete details regarding the training process for A-CRA raters.

Monthly A-CRA Competency is a dichotomous ( $1=$ yes, $0=$ no) measure and indicates whether or not a randomly selected session recording was rated at or above the minimum level of competence required for ACRA certification (i.e., rating of 3 or higher on all components of the procedure). As described in the A-CRA coding manual [78], each component of an attempted A-CRA procedure is rated using the following categories: 1 = poor, 2 = needs improvement, 3 = satisfactory, 4 = very good, and $5=$ excellent. To ensure a representative sample of session recordings, only those therapist participants who submitted at least $80 \%$ or more of treatment sessions (minimum of five sessions per month) are eligible to have a session randomly selected and rated for competence. This requirement was implemented in order to reduce the risk of therapists trying to manipulate the criterion being reinforced by only uploading those sessions they expected would pass the competency rating.

\section{Adolescent intake and follow-up measures}

In addition to examining the extent to which monetary incentives improve treatment implementation (i.e., delivery of Target A-CRA, demonstration of Monthly ACRA Competency), a third aim of the RTP study is to examine the extent to which these two implementation measures impacted treatment outcome for the adolescent clients. Being 'in recovery' (i.e., no past month alcohol or other drug use, abuse, or dependence symptoms while living in the community) was selected as the primary outcome of interest, as is consistent with the primary clinical outcome used in the Cannabis Youth Treatment (CYT) study [8]. Intake and follow-up versions of this measure were collected using the GAIN [79], which is a comprehensive biopsychosocial assessment designed to integrate research and clinical assessment into one structured interview. The GAIN's main scales have been shown to demonstrate good internal consistency (alpha greater than 0.90 on main scales, 0.70 on subscales), test-retest reliability (Rho greater than 0.70 on days/problem counts, kappa greater than 0.60 on categorical measures), and to be highly correlated with measures of use based on timeline follow-back methods, urine tests, collateral reports, treatment records, and blind psychiatric diagnoses (rho of 0.70 or more, kappa of 0.60 or more) [79-81]. GAIN data were collected as part of the AAFT project's evaluation and were de-identified prior to being used as part of the RTP study. In order to access this data, the study group sought and received a signed data sharing agreement from each site that explicitly allowed the use of the deidentified adolescent data for the purposes of research, public health, or healthcare operations.

\section{Cost measures}

Parallel to the RTP study's effectiveness-related aims is a set of aims related to CE. The primary focus of the economic analyses is to compare the operating and reinforcement costs between the IAU and the P4P groups. Operating costs are defined as costs associated with treatment delivery, and reinforcement costs are defined as costs associated with reinforcing superior delivery/ implementation of treatment. Additionally, in order to be able to better interpret the findings, it also was necessary to collect information on training costs.

The Treatment Cost Assessment Tool (TCAT) was used to determine operating costs of delivering A-CRA and ACC at each participating AAFT site. The TCAT was developed by Brandeis University in collaboration with Texas Christian University [82] and is an extension of the methods used in the Cost Study of the Alcohol and Drug Services Study (ADSS) [83,84]. The study's TCAT version is a Microsoft ${ }^{\oplus}$ Excel-based workbook that is used to collect information related to a site's clinical activity (e.g., number of clients served, average direct time per treatment session), personnel costs (e.g., percentage of time spent on clinical activities, salary), and non-personnel costs (e.g., supplies, transportation). In contrast to the operating costs, the reinforcement costs are the costs associated with providing the monetary incentives to therapists as part of the RTP study, and are calculated as a total of the payments themselves times $(1+$ overhead rate of Chestnut Health Systems). The overhead cost is included to reflect the resource costs in administering incentives (e.g., verifying incentive criterion and documenting payments). In the course of completing the TCAT, we will gather data about the persons, steps, and time involved in administering incentives, so we can refine the estimate of administrative costs. Because the clinical training for the AAFT initiative is being funded through a separate CSAT contract, the training costs are those costs incurred by the training contractor in delivering the AAFT training and technical assistance (e.g., trainers, logistics, travel expenses of trainees). A cost per therapist trained will be computed by taking the total cost of the training effort divided by the number of AAFT therapists trained. 


\section{Analytic plan \\ Effectiveness-related analyses}

Because of the multilevel nature of the data, Hierarchical Linear Modeling (HLM) [85], which is able to handle this type of data by allowing the relationship between the variables of interest to vary by higher-level groupings (i.e., therapists and/or sites), will be used to analyze the effectiveness-related hypotheses. For H1.1 (i.e., Target A-CRA is more likely for adolescents in the P4P group), the main independent variable is group assignment (IAU versus P4P), and the dependent variable is whether adolescents received Target A-CRA. Adolescents are at level one, therapists are at level two, and sites are at level three. For Hypothesis H1.2 (i.e., Monthly A-CRA Competence is more likely for therapists in the P4P group), the main independent variable is group assignment (IAU versus P4P), and the dependent variable is the percentage of months therapists demonstrated A-CRA competence. Here, therapists are at the lowest level (i.e., level one), and sites are at the next highest level (i.e., level two). For Hypothesis H1.3 (i.e., being in recovery after intake is more likely for adolescents in the P4P group), the main independent variable is group assignment (IAU versus $\mathrm{P} 4 \mathrm{P}$ ), and the dependent variable is whether adolescents are in recovery post-intake. Again, adolescents are at level one, therapists are at level two, and sites are at level three.

\section{Cost effectiveness-related analyses}

As is the usual case in $\mathrm{CE}$ analyses, we hypothesize that the experimental P4P group will be more expensive, but more effective relative to the IAU group. In order to test this general hypothesis, we relate the cost of reinforcement to its impact on each of the study's effectiveness-related hypotheses described in the previous section. In addition to noting whether the P4P group was statistically superior to the IAU group on each outcome, we will report the cost per adolescent receiving Target A-CRA, cost per month of demonstrated A-CRA competence, and cost per adolescent in recovery after intake. Using the notation of Glick and colleagues [86], the CE measure for the RTP study is the ratio of cost ( $i$. $e$., the difference between the average cost per individual in $\mathrm{P} 4 \mathrm{P}$ and the average cost per individual in IAU, denoted by $\mathrm{C}$ ) divided by effectiveness (i.e., the comparable difference on effectiveness, denoted by Q). That is, $\mathrm{CE}=\mathrm{C} / \mathrm{Q}$. Our basic $\mathrm{CE}$ measure is the $\mathrm{CE}$ of reinforcement using each of the measures in this study (i.e., cost per adolescent who receives Target A-CRA; cost per month of demonstrated A-CRA competence; and cost per adolescent in recovery after intake). Each of these measures will be calculated as $C E(P 4 P)=C$ (P4P)/Q(P4P). Here, C (reinforcement) is the difference in costs between the P4P and IAU groups, converted to the appropriate scale, and $\mathrm{Q}(\mathrm{P} 4 \mathrm{P})$ is the corresponding difference in outcomes. Within CE measures, the numerator of each measure is the net cost (difference in cost per client and the grand mean), and the denominator is the net effectiveness (difference in the outcome per client and the grand mean) for each of the three respective outcomes (\% of months of A-CRA/ACC competence; \% of adolescents receiving Effective Threshold of A-CRA/ACC, and \% of adolescents in recovery after intake).

\section{Discussion}

The RTP study is one response to recommendations to examine the impact of P4P on improving the quality of care [87], and it represents the largest known randomized experiment to date to evaluate the impact of P4P methods at the staff level within the substance abuse treatment field. The study design was based on taking into consideration key P4P design elements as described by Rosenthal and Dudley [88], who have identified five key design elements of P4P programs. The following section briefly describes each of these elements and how they have been addressed in this study.

\section{Individual versus group}

The first element relates to whether the P4P initiative targets individuals or the organization. According to Rosenthal and Dudley [89], 14\% of programs focused on individuals alone, $25 \%$ focused on both individuals and groups, and $61 \%$ focused on groups alone. However, consistent with their recommendation to provide incentives to the group or individual that is most responsible for the targeted behavior, therapists were selected as part of the RTP study given they are the ones who must ultimately implement the treatment with clients.

\section{Paying the right amount}

In order for an incentive to be effective, it must be commensurate with the costs in time and effort associated with achieving the targeted behavior. This is similar to the concept of financial salience being measured as part of the RTP study. Importantly, given the paucity of studies within the field of alcohol and drug treatment that have used P4P methods, determining appropriate incentive amounts was perhaps the most difficult aspect of designing the study. That is, incentive amounts selected had to simultaneously be large enough to significantly improve therapist performance, and small enough to be considered within a practical range for communitybased treatment providers to implement.

Calculations suggested that full-time therapists in the P4P condition would earn on average an amount between $\$ 1,404$ and $\$ 2,412$ per 12 -month period, which equated to approximately $4 \%$ to $7 \%$ of an average annual therapist salary of $\$ 35,000$. While we believe these amounts are within a range that is practical for community-based treatment providers, the study will help us 
learn whether or not these incentives are large enough to impact performance.

\section{Selecting high-impact performance measures}

The third element relates to linking the incentives to performance measures that are meaningful and/or based upon sound scientific evidence and is similar to the concept of clinical relevance being measured as part of the RTP study. While research to date has provided only limited empirical support for the relationship between competency and outcomes, we believe this targeted behavior has considerable intuitive appeal and therefore will be perceived by therapists as being clinically relevant. Similarly, we believe therapists will find Target ACRA to be a clinically meaningful performance measure, especially given the recent empirical evidence indicating that exposure to A-CRA procedures mediates the relationship between treatment retention and outcome [65].

\section{Making payment reward all high-quality care}

The fourth element relates to rewarding all who meet or exceed some threshold level of 'high quality care' as opposed to rewarding only the top performers (e.g., top $10 \%)$-the latter of which tends to create competition between providers and consequently decrease collaboration and sharing of ideas. Consistent with this recommendation, both Target A-CRA and Demonstration of Monthly A-CRA Competence represent threshold levels of high quality care, and achievement of one or both by one therapist does not reduce the opportunity for another therapist to also achieve the incentive.

\section{Prioritizing quality improvement for underserved populations}

The fifth element relates to reducing disparities in health and healthcare quality by offering relatively larger incentives for providing high-quality care to disadvantaged populations. Although the incentive amounts offered as part of the RTP did not differ for underserved populations, it may be possible to examine if there were differential rates of achievement of the targeted behaviors by race/ethnicity and/or gender.

\section{Study strengths and weaknesses}

In addition to the use of random assignment, the RTP study has several other strengths. For example, a unique strength of the RTP study is the level of standardization in regard to the funding and training provided to the 29 participating agencies and their therapists. Specifically, because CSAT's approximately $\$ 30$ million dollar AAFT initiative provided each of its grantees with close to $\$ 300,000$ per year (for three years) as well as a comprehensive training and technical assistance package (via a separate training contract), the AAFT initiative provided an ideal opportunity to focus on examining the effectiveness and CE of P4P to improve EBT implementation and subsequent treatment outcomes for clients. Other strengths of the study include its: use of a theoretically- based conceptual framework; multi-site design; relatively large sample size; independent verification of therapist achievement of targeted behaviors; longitudinal assessment of therapist attitudes and client outcomes; inclusion of CE analyses; and hypothesis-driven multilevel analytic plan. Like all studies, however, the RTP study also has some limitations that must be acknowledged. First, although larger than any other known P4P experiment conducted to date, a greater number of sites and therapists would provide more statistical power and better generalizability. A second limitation of the study is that randomization was conducted by grantee rather than by therapist. However, as discussed previously, we believe the potential disadvantages associated with randomizing therapists within site (e.g., compensatory rivalry, resentful demoralization) outweighed its advantages. Finally, because the targets being reinforced as part of this study are specific to the delivery of ACRA procedures, the findings from this study may not generalize to other interventions and/or healthcare or behavioral health settings.

\section{Next steps}

Although the recruitment and randomization of AAFT grantees has been completed, it is possible that additional therapists will be recruited as AAFT grantees hire new therapists. Indeed, this aspect of the RTP study is interesting in that in direct contrast to most studies, where attrition decreases statistical power, attrition actually has the potential to increase statistical power, given that therapists are typically replaced. Additionally, our research team continues to monitor therapist achievement of both Target A-CRA and Monthly A-CRA Competence and to administer both the therapist surveys and the TCAT. Given the study has just ended its first of three years, it will be some time before we are able to report on the impact of the incentives on therapist achievement of the targeted behaviors and on subsequent client outcomes. However, we plan to begin testing other parts of our conceptual framework. For example, we plan to examine the extent to which therapists' attitudes toward the incentives and TPB constructs explain variance in their intentions to achieve these behaviors. Given the increasing need to not only understand what interventions work, but how they work $[89,90]$, research to understand the mechanisms through which reinforcing therapist performance via monetary incentives work is a critically important step.

\footnotetext{
Acknowledgements

This work was supported by the National Institute on Alcohol Abuse and Alcoholism (R01 AA017625) and the Substance Abuse and Mental Health Services Administration's Center for Substance Abuse Treatment (TI17589, TI17604, TI17605, TI17638; TI17646, TI17673, TI17702, TI17719, TI17724, TI17728, TI17742, TI17744, TI17751, TI17755, TI17761, TI17763, TI17765, TI17769, TI17775, TI17779, TI17786, TI17788, TI17812, TI17817, TI17830,
} 
TI17847, TI17864, TI19313, TI19323, and contract no. 270-07-0191). The opinions are those of the authors and do not represent the position of the government. The authors also wish to thank Christin Bair for assistance in coordinating this project and Stephanie Merkle for assistance in preparing this manuscript for submission.

\section{Author details}

${ }^{1}$ Lighthouse Institute, Chestnut Health Systems, Normal, IL, USA. ${ }^{2}$ Schneider Institute for Health Policy, Heller School, Brandeis University, Waltham MA, USA.

\section{Authors' contributions}

BRG conceived of and developed the study protocol, leads the study implementation, and drafted this manuscript. SHG, MDG, MLD, and DSS helped develop the study protocol and contributed to drafting this manuscript. All authors read and approved the final manuscript.

\section{Competing interests}

The authors declare that they have no competing interests.

Received: 3 November 2009

Accepted: 26 January 2010 Published: 26 January 2010

\section{References}

1. Dennis ML, Scott CK: Managing addiction as a chronic condition. Addict Sci Clin Pract 2007, 4:45-55.

2. Dennis ML, Scott CK, Funk R, Foss MA: The duration and correlates of addiction and treatment careers. J Subst Abuse Treat 2005, 28(Suppl 1): S51-S62.

3. McLellan AT, Lewis DC, O'Brien CP, Kleber HD: Drug dependence, a chronic medical illness: implications for treatment, insurance, and outcomes evaluation. JAMA 2000, 284:1689-1695.

4. Dennis M, Babor TF, Roebuck MC, Donaldson J: Changing the focus: the case for recognizing and treatment cannabis use disorders. Addiction 2002, 97(Suppl 1):4-15.

5. Brown SA, D'Amico EJ, McCarthy DM, Tapert SF: Four-year outcomes from adolescent alcohol and drug treatment. J Stud Alcohol 2001, 62:381-388.

6. Liddle HA, Dakof GA, Parker K, Diamond GS, Barrett K, Tejeda M: Multidimensional family therapy for adolescent drug abuse: results of a randomized clinical trial. Am J Drug Alcohol Abuse 2001, 27:651-688.

7. Liddle HA, Rowe CL, Dakof GA, Ungaro RA, Henderson CE: Early intervention for adolescent substance abuse: pretreatment to posttreatment outcomes of a randomized clinical trial comparing multidimensional family therapy and peer group treatment. J Psychoactive Drugs 2004, 36:49-63.

8. Dennis M, Godley SH, Diamond G, Tims FM, Babor T, Donaldson J, Liddle H, Titus JC, Kaminer Y, Webb C, Hamilton N, Funk R: The Cannabis Youth Treatment (CYT) study: main findings from two randomized trials. J Subst Abuse Treat 2004, 27:197-213.

9. Godley MD, Godley SH, Dennis ML, Funk RR, Passetti LL: The effect of assertive continuing care on continuing care linkage, adherence and abstinence following residential treatment for adolescents with substance use disorders. Addiction 2007, 102:81-93.

10. Henggeler SW, Clingempeel WG, Brondino MJ, Pickrel SG: Four-year followup of multisystemic therapy with substance-abusing and substancedependent juvenile offenders. J Am Acad Child Adolesc Psychiatry 2002, 41:868-874.

11. Jainchill N, Hawke J, De Leon G, Yagelka J: Adolescents in therapeutic communities: one-year posttreatment outcomes. J Psychoactive Drugs 2000, 32:81-94.

12. Muck R, Zempolich KA, Titus JC, Fishman M, Godley MD, Schwebel R: An overview of the effectiveness of adolescent substance abuse treatment models. Youth Soc 2001, 33:143-168.

13. Waldron HB, Slesnick N, Brody JL, Turner CW, Peterson TR: Treatment outcomes for adolescent substance abuse at 4- and 7-month assessments. J Consult Clin Psychol 2001, 69:802-813.

14. Williams RJ, Chang SY: A comprehensive and comparative review of adolescent substance abuse treatment outcome. Clin Psychol Sci Prac 2000, 7:138-166
15. Garner BR: Research on the diffusion of evidence-based treatments within substance abuse treatment: a systematic review. J Subst Abuse Treat 2009, 36:376-399.

16. Gotham HJ: Diffusion of mental health and substance abuse treatments: development, dissemination, and implementation. Clin Psychol Sci Prac 2004, 11:160-176.

17. Lamb S, Greenlick MR, McCarty D: Bridging the Gap Between Practice and Research: Forging Partnerships with Community-Based Drug and Alcohol Treatment Washington, DC: National Academy Press 1998.

18. Miller WR, Sorensen $J L$, Selzer JA, Brigham GS: Disseminating evidencebased practices in substance abuse treatment: a review with suggestions. J Subst Abuse Treat 2006, 31:25-39.

19. Knudsen HK, Ducharme L, Roman PM: Early adoption of buprenorphine in substance abuse treatment centers: data from the private and public sectors. J Subst Abuse Treat 2006, 30:363-373.

20. Knudsen HK, Ducharme $L$, Roman PM: The adoption of medications in substance abuse treatment: associations with organizational characteristics and technology clusters. Drug Alcohol Depend 2007, 87:164-174.

21. Aarons GA: Mental health provider attitudes toward adoption of evidence-based practice: the Evidence-Based Practice Attitude Scale (EBPAs). Ment Health Serv Res 2004, 6:61-74.

22. McGovern MP, Fox TS, Xie H, Drake RE: A survey of clinical practices and readiness to adopt evidence-based practices: dissemination research in an addiction treatment system. J Subst Abuse Treat 2004, 26:305-312.

23. Willenbring ML, Kivlahan D, Kenny M, Grillo M, Hagedorn H, Postier A: Beliefs about evidence-based practices in addiction treatment: a survey of Veterans Administration program leaders. J Subst Abuse Treat 2004, 26:79-85.

24. Fixsen DL, Naoom SF, Blase KA, Friedman RM, Wallace F: Implementation Research: A Synthesis of the Literature Tampa, FL: University of South Florida, Louis de la Parte Florida Mental Health Institute, The National Implementation Research Network (FMHI Publication \#231) 2005.

25. Simpson DD: A conceptual framework for transferring research to practice. J Subst Abuse Treat 2002, 22:171-182.

26. Simpson DD, Flynn PM: Moving innovations into treatment: a stagebased approach to program change. J Subst Abuse Treat 2007, 33:111-120.

27. Thomas CP, Wallack SS, Lee S, McCarty D, Swift R: Research to practice: adoption of naltrexone in alcoholism treatment. J Subst Abuse Treat 2003, 24:1-11.

28. Edmundson E Jr, McCarty D: Implementing Evidence-Based Practices for Treatment of Alcohol and Drug Disorders Binghamton, NY: Haworth Medical Press 2005.

29. Gotham HJ: Advancing the implementation of evidence-based practices into clinical practice: how do we get there from here?. Prof Psychol Res Pr 2006, 37:606-613.

30. Lipsey MW: What can you build with thousands of bricks? Musings on the cumulation of knowledge in program evaluation. New Directions for Evaluation 1997, 76:7-23.

31. Beutler LE: The psychotherapist as a neglected variable in psychotherapy: an illustration by reference to the role of therapist experience and training. Clin Psychol Sci Prac 1997, 4:44-52.

32. Garfield SL: The therapist as a neglected variable in psychotherapy research. Clin Psychol Sci Prac 1997, 4:40-43.

33. Miller WR, Yahne CE, Moyers TB, Martinez J, Pirritano M: A randomized trial of methods to help clinicians learn motivational interviewing. J Consult Clin Psychol 2004, 72:1050-1062.

34. Sholomskas DE, Syracuse-Siewert G, Rounsaville BJ, Ball SA, Nuro KF, Carroll KM: We don't train in vain: a dissemination trial of three strategies of training clinicians in cognitive-behavioral therapy. J Consult Clin Psychol 2005, 73:106-115.

35. Walters ST, Matson SA, Baer JS, Ziedonis DM: Effectiveness of workshop training for psychosocial addiction treatments: a systematic review. J Subst Abuse Treat 2005, 29:283-293.

36. Shaw BF, Elkin I, Yamaguchi J, Olmsted M, Vallis TM, Dobson KS, Lowery A, Sotsky SM, Watkins JT, Imber SD: Therapist competence ratings in relation to clinical outcome in cognitive therapy of depression. J Consult Clin Psychol 1999, 67:837-846.

37. Crits-Christoph P, Mintz J: Implications of therapist effects for the design and analysis of comparative studies of psychotherapies. J Consult Clin Psychol 1991, 59:20-26. 
38. Crits-Christoph P, Baranackie K, Kurcias JS, Beck AT, Carroll K, Perry K Luborsky L, McLellan AT, Woody GE, Thompson L, Gallagher D, Zitrin C: Meta-analysis of therapist effects in psychotherapy outcome studies. Psychother Res 1991, 1:81-91.

39. Crits-Christoph P, Gallop R: Therapist effects in the National Institute of Mental Health Treatment of Depression Collaborative Research Program and other psychotherapy studies. Psychother Res 2006, 16:178-181.

40. Kim D-M, Wampold BE, Bolt DM: Therapist effects in psychotherapy: a random-effects modeling of the National Institute of Mental Health Treatment of Depression Collaborative Research Program data. Psychother Res 2006, 16:161-172.

41. Najavits LM, Weiss RD: Variations in therapist effectiveness in the treatment of patients with substance use disorders: an empirical review. Addiction 1994, 89:679-688.

42. Luborsky L, Barber J, Siqueland L, McLellan AT, Woody G: Establishing a therapeutic alliance with substance abusers. Beyond the Therapeutic Alliance: Keeping the Drug-Dependent Individual in Treatment Washington, DC: U.S. Government Printing OfficeOnken LS, Blaine JD, Boren JJ 1997, 233-240.

43. Condelli WS, Fairbank JA, Dennis ML, Rachal JV: Cocaine use by clients in methadone programs: significance, scope, and behavioral interventions. J Subst Abuse Treat 1991, 8:203-212.

44. Dennis ML: Ethical and practical randomized field experiments. Handbook of Practical Program Evaluation San Francisco: Jossey-BassWholey JS, Hatry HP, Newcomer KE 1994, 155-197.

45. Higgins ST, Silverman KE: Motivating Behavior Change Among Illicit Drug Abusers: Research on Contingency Management Interventions Washington, DC: American Psychological Association 1999.

46. Institute of Medicine: Bridging the Gap Between Practice and Research: Forging Partnerships with Community-Based Drug and Alcohol Treatment Washington, DC: National Academy Press 1998.

47. Lussier JP, Heil SH, Mongeon JA, Badger GJ, Higgins ST: A meta-analysis of voucher-based reinforcement therapy for substance use disorders. Addiction 2006, 101:192-203.

48. Miller WR, Wilbourne PL: Mesa Grande: a methodological analysis of clinical trials of treatments for alcohol use disorders. Addiction 2002, 97:265-277.

49. Prendergast M, Podus D, Finney J, Greenwell L, Roll J: Contingency management for treatment of substance use disorders: a meta-analysis. Addiction 2006, 101:1546-1560.

50. Stitzer M, Petry $\mathrm{N}$ : Contingency management for treatment of substance abuse. Annu Rev Clin Psychol 2006, 2:411-434.

51. Jenkins GD Jr, Mitra A, Gupta N, Shaw JD: Are financial incentives related to performance? A meta-analytic review of empirical research. J Appl Psychol 1998, 83:777-787.

52. Condly SJ, Clark RE, Stolovitch HD: The effects of incentives on workplace performance: a meta-analytic review of research studies. Performance Improvement Quarterly 2003, 16:46-63.

53. Bucklin BR, Dickinson AM: Individual monetary incentives: a review of different types of arrangements between performance and pay. Journal of Organizational Behavior Management 2001, 21:45-137.

54. Rynes SL, Gerhart B, Parks L: Personnel psychology: performance evaluation and pay for performance. Annu Rev Psychol 2005, 56:571-600.

55. Dudley RA, Frolich A, Robinowitz DL, Talavera JA, Broadhead P, Luft HS: Strategies to Support Quality-Based Purchasing: A Review of the Evidence. Technical Review 10 (Prepared by the Stanford University of California San Francisco Evidence-based Practice Center under Contract No. 290-02-0017). AHRQ Publication No. 04-0057. Rockville, MD: Agency for Healthcare Research and Quality 2004

56. Bremer RW, Scholle SH, Keyser D, Knox Houtsinger JV, Pincus HA: Pay for performance in behavioral health. Psychiatr Serv 2008, 59:1419-1429.

57. Andrzejewski ME, Kirby KC, Morral AR, Iguchi MY: Technology transfer through performance management: the effects of graphical feedback and positive reinforcement on drug treatment counselors' behavior. Drug Alcohol Depend 2001, 63:179-186.

58. Shepard DS, Calabro JAB, Love CT, McKay JR, Tetreault J, Yeom HS: Counselor incentives to improve client retention in an outpatient substance abuse aftercare program. Adm Policy Ment Health \& Ment Health Serv Res 2006, 33:629-635.
59. McLellan AT, Kemp J, Brooks A, Carise D: Improving public addiction treatment through performance contracting: the Delaware experiment. Health Policy 2008, 87:296-308.

60. Ajzen I: The theory of planned behavior. Organ Behav Hum Decis Process 1991, 50:179-211.

61. Meterko M, Young GJ, White B, Bokhour BG, Burgess JF Jr, Berlowitz D, Gulden MR, Seibert MN: Provider attitudes toward pay-for-performance programs: development and validation of a measurement instrument. Health Serv Res 2006, 41:1959-1978.

62. James LR, Jones AP: Organizational climate: a review of theory and research. Psychol Bull 1974, 81:1096-1112.

63. Weisner C, McLellan T, Barthwell A, Blitz C, Catalano R, Chalk M, Chinnia L, Collins RL, Compton W, Dennis ML, Frank R, Hewitt W, Inciardi JA, Lightfoot M, Montoya I, Sterk CE, Wood J, Pintello D, Volkow M, Michaud SE: Report of the Blue Ribbon Task Force on Health Services Research at the National Institute on Drug Abuse Rockville, MD: National Institute on Drug Abuse 2004.

64. Hunt GM, Azrin NH: A community-reinforcement approach to alcoholism. Behav Res Ther 1973, 11:91-104.

65. Garner BR, Godley SH, Funk RR, Dennis ML, Smith JE, Godley MD: Exposure to Adolescent Community Reinforcement Approach treatment procedures as a mediator of the relationship between adolescent substance abuse treatment retention and outcome. J Subst Abuse Treat 2009, 36:252-264.

66. Garner BR, Godley MD, Funk RR, Dennis ML, Godley SH: The impact of continuing care adherence on environmental risks, substance use, and substance-related problems following adolescent residential treatment. Psychol Addict Behav 2007, 21:488-497.

67. Godley MD, Godley SH, Dennis ML, Funk R, Passetti LL: Preliminary outcomes from the assertive continuing care experiment for adolescents discharged from residential treatment. J Subst Abuse Treat 2002, 23:21-32.

68. Slesnick N, Prestopnik JL, Meyers RJ, Glassman M: Treatment outcome for street-living, homeless youth. Addict Behav 2007, 32:1237-1251.

69. Barber JP, Crits-Christoph P, Luborsky L: Effects of therapist adherence and competence on patient outcome in brief dynamic therapy. J Consult Clin Psychol 1996, 64:619-622.

70. Hogue A, Henderson CE, Dauber S, Barajas PC, Fried A, Liddle HA: Treatment adherence, competence, and outcome in individual and family therapy for adolescent behavior problems. J Consult Clin Psychol 2008, 76:544-555.

71. Shadish WR, Cook TD, Campbell DT: Experimental and Quasi-Experimental Designs for Generalized Causal Inference Boston, MA: Houghton Mifflin Company 2002.

72. Stout RL, Wirtz PW, Carbonari JP, Del Boca FK: Ensuring balanced distribution of prognostic factors in treatment outcome research. J Stud Alcohol Suppl 1994, 12:70-75.

73. Weiss DJ, Dawis RV, England GW, Lofquist LH: Manual for the Minnesota Satisfaction Questionnaire Minneapolis, MN: University of Minnesota, Industrial Relations Center 1967.

74. Heneman HG III, Schwab DP: Pay satisfaction: its multidimensional nature and measurement. Int J Psychol 1985, 20:129-141.

75. Lehman WEK, Greener JM, Simpson DD: Assessing organizational readiness for change. J Subst Abuse Treat 2002, 22:197-209.

76. Godley SH, Meyers RJ, Smith JE, Godley MD, Titus JC, Karvinen T, Dent G, Passetti L, Kelberg P: The Adolescent Community Reinforcement Approach (ACRA) for Adolescent Cannabis Users (Cannabis Youth Treatment (CYT) Manual Series, Vol. 4) Rockville MD: Center for Substance Abuse Treatment, Substance Abuse and Mental Health Services Administration 2001.

77. Garner BR, Barnes B, Godley SH: Monitoring fidelity in the Adolescent Community Reinforcement Approach (A-CRA): the training process for A-CRA raters. Journal of Behavior Analysis in Health, Sports, Fitness, and Medicine 2009, 2:43-54.

78. Smith JE, Lundy SL, Gianini L: Community Reinforcement Approach (CRA) and Adolescent Community Reinforcement Approach (A-CRA) Coding Manual Albuquerque, NM: University of New Mexico 2007.

79. Dennis ML, Titus JC, White M, Unsicker J, Hodgkins D: Global Appraisal of Individual Needs (GAIN): Administration Guide for the GAIN and Related Measures (Version 5) Bloomington, IL: Chestnut Health Systems 2003.

80. Dennis ML, Chan Y-F, Funk RR: Development and validation of the GAIN Short Screener (GSS) for internalizing, externalizing and substance use 
disorders and crime/violence problems among adolescents and adults. Am J Addict 2006, 15:80-91.

81. Dennis ML, Ives ML, White MK, Muck RD: The Strengthening Communities for Youth (SCY) initiative: a cluster analysis of the services received, their correlates and how they are associated with outcomes. J Psychoactive Drugs 2008, 40:3-16.

82. Flynn PM, Broome KM, Beaston-Blaakman A, Knight DK, Horgan CM, Shepard DS: Treatment Cost Analysis Tool (TCAT) for estimating costs of outpatient treatment services. Drug Alcohol Depend 2009, 100:47-53.

83. Shepard DS, Beaston-Blaakman A, Horgan C: The ADSS Cost Study: Costs of Substance Abuse Treatment in the Specialty Sector. DHHS Publication No. SMA 03-3762, Analytic Series: A-20. Rockville, MD: Substance Abuse and Mental Health Services Administration, Office of Applied Studies 2003http:// www.oas.samhsa.gov/adss/ADSSCostStudy.pdf.

84. Shepard DS, Beaston-Blaakman A, Horgan C: An Interactive Approach to Estimating Costs of Drug and Alcohol Treatment: The ADSS Cost Study. . Presented at Addiction Health Services Research Conference, Santa Monica, CA, October 25-26; 2005

85. Raudenbush SW, Bryk AS: Hierarchical Models: Applications and Data Analysis Methods Thousand Oaks, CA: Sage, 22002.

86. Glick HA, Doshi JA, Sonnad SS, Polsky D: Economic Evaluation in Clinical Trials New York: Oxford University Press 2007.

87. Institute of Medicine: Rewarding Provider Performance: Aligning Incentives in Medicare Washington, DC: National Academy Press 2007.

88. Rosenthal MB, Dudley RA: Pay-for-performance: will the latest payment trend improve care?. JAMA 2007, 297:740-744.

89. Kazdin AE, Nock MK: Delineating mechanisms of change in child and adolescent therapy: methodological issues and research recommendations. J Child Psychol Psychiatry 2003, 44:1116-1129.

90. La Greca AM, Silverman WK, Lochman JE: Moving beyond efficacy and effectiveness in child and adolescent intervention research. J Consult Clin Psychol 2009, 77:373-382.

doi:10.1186/1748-5908-5-5

Cite this article as: Garner et al:: The Reinforcing Therapist Performance (RTP) experiment: Study protocol for a cluster randomized trial. Implementation Science 2010 5:5.

\section{Submit your next manuscript to BioMed Central and take full advantage of:}

- Convenient online submission

- Thorough peer review

- No space constraints or color figure charges

- Immediate publication on acceptance

- Inclusion in PubMed, CAS, Scopus and Google Scholar

- Research which is freely available for redistribution

Submit your manuscript at www.biomedcentral.com/submit
Biomed Central 